\title{
Two Cases of Isolated ACTH Deficiency Presenting As Hyponatremia - Case Report
}

\author{
Bhardwaj L.M. ${ }^{1}$, Bhattacharyya P. C. ${ }^{2}$, Borthakur S. ${ }^{3}$, Sarma A. ${ }^{4}$, Barua S. ${ }^{5}$ \\ ${ }^{1}$ Dr. Lalit Mohan Bhardwaj, DNB PGT, General Medicine, Guwahati, Assam, ${ }^{2}$ Dr. P. C. Bhattacharyya, Senior \\ Consultant, ${ }^{3}$ Dr. Swapnav Borthakur, Senior Consultant, ${ }^{1,2,3}$ above all authors are affiliated with Department of \\ Medicine, ${ }^{4}$ Dr. Anuj Sarma, Senior Consultant, Department of Anaesthesia and Critical Care, ${ }^{5}$ Dr. Sumitav \\ Barua, Senior Consultant, Department of Medicine, all authors are affiliated with Down Town Hospital, \\ Guwahati, Assam, India.
}

Address for Correspondence: Dr. Lalit Mohan Bhardwaj, Email: dr.lalitmohan7@gmail.com

\begin{abstract}
Non-specific symptoms such as asthenia, anorexia, unintentional weight loss, nausea/vomiting particularly in the elderly population are often overlooked both by caretakers and physicians. Deteriorating general health and neuro-psychiatric symptoms are often attributed to depression in the elderly population. The most common electrolyte abnormality, hyponatremia is again more common in the elderly population. Often neglected chronic hyponatremia remains asymptomatic in many cases. Once hyponatremia is detected clinicians should establish a proper diagnosis before supplementation. Failure to diagnose such cases will lead to repeated hospitalization, poor quality of life, wastage of resources and even death. Isolated ACTH deficiency (IAD) is a rare disorder and potentially fatal. IAD can present rarely as hyponatremia and diagnosis can easily be missed if not suspected. IAD may not be as rare as earlier thought as more and more such cases are been reported. Here we report two cases of generalized weakness and nausea; they were repeatedly hospitalized and treated for hyponatremia and ultimately diagnosed as IAD in our hospital.
\end{abstract}

Key words: Isolated ACTH deficiency, Hyponatremia, IAD, Secondary adrenal insufficiency.

\section{Introduction}

Isolated ACTH deficiency (IAD) is a rare disorder. Diagnosis is made in presence of secondary adrenal insufficiency (AI) with low or absent cortisol production, normal secretion of pituitary hormones other than ACTH and there are no structural pituitary defects. Patients of IAD usually present with nonspecific symptoms such as asthenia, anorexia, unintentional weight loss, nausea/ vomiting, hyponatremia, pyrexia [1], neuropsychiatric symptoms [2] and tendency towards hypoglycemia [3].

Studies have shown that these patients can present as pyrexia of unknown origin which responds to corticosteroids [4]. These nonspecific symptoms may lead to repeated hospitalization, missed diagnosis, poor quality of life. Here we report two

Manuscript received: $20^{\text {th }}$ July 2017

Reviewed: $31^{\text {st }}$ July 2017

Author Corrected: $10^{\text {th }}$ August 2017

Accepted for Publication: $17^{\text {th }}$ August 2017 such cases of generalized weakness and nausea; they were repeatedly hospitalized and treated for hyponatremia, which was ultimately found to have IAD. Both patients responded to glucocorticoid therapy.

\section{Case Report 1}

A 71 years old male patient, retired bank employee was known hypertensive and diabetic since last 10 years. He presented with generalized weakness, urinary frequency, fever and cough since last 10 days. Currently he is taking amlodipine $5 \mathrm{mg}$ for hypertension in a once daily dosing. He was hospitalized twice for similar episodes in last 2 years. During hospitalization, he was treated with IV 3\% sodium chloride for hyponatremia. This time he came to our hospital with above complaints. He also had tremors and forgetfulness since last 7-8 months. 
Clinical examination- $\mathrm{He}$ was conscious but disoriented, febrile (Temp. $101.3^{\circ} \mathrm{F}$ ), heart rate-92 bpm, BP-140/90 mm of $\mathrm{Hg}$; $\mathrm{He}$ was ambulatory before 10 days then he found difficulty in walking and he was unable to sit without support by last 4 days.

Bilateral planter flexor, tone slightly decreased and motor power $3 / 5$ in all four limbs. Other general and systemic examination was unremarkable.

Investigation- TLC - 7200/cumm (P-48\%, L$41 \%, \mathrm{M}-07 \%, \mathrm{E}-1), \mathrm{Hb}-11.9 \mathrm{gm} \%$, ESR - 40 $\mathrm{mm}$, platelet count -2.2 lacs, S.creatinine -0.67 $\mathrm{mg} / \mathrm{dl}, \mathrm{S} . \mathrm{Na}^{+}-118.6 \mathrm{meq} / \mathrm{l}, \mathrm{S} . \mathrm{k}^{+}-3.72 \mathrm{meq} / \mathrm{l}, \mathrm{FBS}-$ $89 \mathrm{mg} / \mathrm{dl}$, HBA1c-5.65\%, Total PSA- $1.16 \mathrm{ng} / \mathrm{ml}$, Serum osmolality- $252.04 \mathrm{mosm} / \mathrm{kg}$, ECGtrifascicular block, Liver Function Test -within normal limits; Except S. Albumin- $2.74 \mathrm{~g} / \mathrm{dl}$, Thyroid profile- within normal limits. Urine routine examination- within normal limits, Urinary $\mathrm{Na}^{+}$ $72.0 \mathrm{mmol} / \mathrm{L}$, Urinary $\mathrm{K}^{+} 17.7 \mathrm{mmol} / \mathrm{L}$, Urinary osmolality-312.26 mosm $/ \mathrm{kg}$, s. prolactin level- 12 $\mathrm{ng} / \mathrm{ml}$; Serum cortisol (8am)- $25.2 \mathrm{nmol} / 1$ (normal range 123-626), Injection Acton Prolongatum ${ }^{\circledR}$ (available as $5 \mathrm{ml}$ vial with concentration of 60 units per ml) was used for intramuscular ACTH stimulation test.

Twenty five units of ACTH [5] were injected intramuscularly by $40 \mathrm{IU}$ insulin syringe (up to 16 marks) and second blood sample was collected after 60 minutes for estimation of cortisol (612nmol/1).

Plasma Renin Activity- $0.71 \mathrm{ng} / \mathrm{ml} / \mathrm{hr}$ (normal range 0.50-1.9), Plasma ACTH 13 pg/ml (normal <46), S.

Aldosterone 28.90pg/ml (normal range 10-105), Tracheal secretion for culture- Staph. aureus + candida species. Foleys tip for culture- Kleibseilla.

USG Abdomen- within normal limits, HRCT thorax- within Normal Limits. MRI brain- diffuse atrophic changes, mild supratentorial ventriculomegaly, pituitary gland- normal.

Diagnosis and treatment- Diagnosis was made on the basis of history, clinical profile and laboratory parameters as IAD presenting as hyponatremia with lower respiratory tract infection, urinary tract infection, trifasicular block, and hypertension.
He was managed over hydrocortisone, antibiotic, antifungal, antihypertensive and other supportive care. His S. $\mathrm{Na}^{+}$level started improving and reached to normal limits by $3^{\text {rd }}$ day of hydrocortisone therapy. On the day of discharge he was afebrile, conscious, oriented and able to walk without support. Hydrocortisone was gradually tapered.

\section{Case Report 2}

A 70 years old lady non-hypertensive and nondiabetic presented with generalized weakness, reduced appetite, easy fatigability, nausea and vomiting since last 20 days, she was hospitalized two times earlier for similar episodes and treated locally for hyponatremia.

She was not taking any medicines before illness. This time she was referred to our hospital for persistent symptoms and refractory hyponatremia. She was getting IV 3\% sodium chloride twice daily in a peripheral center.

Clinical examination- She was conscious, oriented and afebrile; Pallor+, Heart rate- $82 / \mathrm{min}$, BP$120 / 80 \mathrm{~mm}$ of $\mathrm{Hg}$. She was ambulatory. Other examinations were unremarkable.

Investigation- $\mathrm{S} . \mathrm{Na}^{+}-108 \mathrm{meq} / \mathrm{l}, \mathrm{S} . \mathrm{K}^{+}-2.78$ $\mathrm{meq} / \mathrm{l}, \mathrm{Hb}=8.6 \mathrm{gm} / \mathrm{dl}$, S. creatinine- $0.67 \mathrm{mg} / \mathrm{dl}, \mathrm{S}$. uric acid- $5.5 \mathrm{mg} / \mathrm{dl}$, S. albumin- $3.3 \mathrm{gm} / \mathrm{dl}$, U. $\mathrm{Na}+$ - $158 \mathrm{mmol} / \mathrm{l}$, U. osmolality-332 mosmol $/ \mathrm{kg}$, S. osmolality- $224 \mathrm{mosmol} / \mathrm{kg}, \mathrm{Ca}^{++}-9.0 \mathrm{mg} / \mathrm{dl}, 25-$ $\mathrm{OH}$ vitamin D level- 20ng/dl, $\mathrm{Mg}^{++}-1.07 \mathrm{mg} / \mathrm{dl}$, TC-2400/cumm, ESR-100 mm, S. Iron- $25 \mu \mathrm{g} / \mathrm{dl}, \mathrm{S}$. TSH- $3.58 \mathrm{mU} / \mathrm{l}$, s. prolactin level- $18 \mathrm{ng} / \mathrm{ml}$, S. cortisol level $=78 \mathrm{nmol} / 1$, serum cortisol level after 60 minute of ACTH stimulation test- $772 \mathrm{nmol} / \mathrm{l}, \mathrm{S}$. aldosterone- $2.17 \mathrm{ng} / \mathrm{dl}, \mathrm{P}$. ACTH- $21 \mathrm{pg} / \mathrm{ml}, \mathrm{P}$. renin- $0.84 \mu \mathrm{IU} / \mathrm{ml}$, serum electrophoresis for $\mathrm{M}$ band- absent, X-ray chest- within normal limits, USG abdomen- within normal limits; $\mathrm{Hb}$ electrophoresis- $\mathrm{Hb}$ AE type; CECT abdomenosteoporotic bones with collapse of D12, L4 and L5 vertebrae; MRI Brain- normal, pituitary glandnormal.

Diagnosis and treatment- Diagnosis was made on the basis of history, clinical profile and laboratory parameters as IAD presenting as hyponatremia, osteoporosis, anaemia (HbE trait). 
She was managed over hydrocortisone, supportive care, calcium and vitamin D supplementation and folic acid.

Hypokalemia and hypomagnesemia was thought to be due to vomiting and decreased oral intake which was adequately supplemented. Her $\mathrm{S}$. $\mathrm{Na}^{+}$level started improving and reached to normal limits by $4^{\text {th }}$ day of hydrocortisone therapy. Her weakness, easy fatigability, and vomiting improved. Hydrocortisone was gradually tapered.

\section{Discussion}

Hyponatremia is quite common however most of the patients are asymptomatic and often neglected. It occurs in up to $22 \%$ of hospitalized patients [6]. Clinicians should be mindful of various causes of hyponatremia, some of which can be easily overlooked. Adrenal insufficiency can go undiagnosed if not suspected.

Normally, reduced level of circulatory cortisol level will remove negative feedback on anterior pituitary and eventually ACTH level raises. Lownormal levels of ACTH especially when serum cortisol levels are low indicate secondary AI. This is further supported by normal aldosterone levels. A diagnosis of IAD can be established in these settings when pituitary gland is structurally normal and other anterior pituitary hormones are normal [7]. In both the above-mentioned cases MRI brain was done which revealed structurally normal pituitary gland. As serum TSH and prolactin levels were normal in both the cases and serum sodium level improved with hydrocortisone therapy, diagnosis of IAD was made.

First case presented with gait disturbance and ventriculomegaly features similar to idiopathic normal pressure hydrocephalus (iNPH). However, gait disturbance and dementia are not only seen in iNPH, instead, they are common in elderly individuals. To diagnose iNPH, Evans index should be at least 0.3 and CSF spaces at the high convexity/ midline areas should be narrow relative to Sylvian fissure size.

These findings were not seen in our case; moreover, iNPH is a diagnosis of exclusion. One such case was reported in the literature [2]. In our first case which was previously diabetic on oral hypoglycemic agents (OHAs), his blood sugar started coming down and remained low even without OHAs. The tendency toward hypoglycemia is one of the presentations of AI [3]. In second case the 'refractory hyponatremia' was not refractory anymore once hydrocortisone therapy was started. Her anemia was due to HbE trait and dorso-lumbar disc collapse was an incidental finding. Both cases received IV 3\% sodium chloride for sufficient time period.

However, there was no significant elevation in serum sodium level. Once the proper diagnosis was made and hydrocortisone (100 mg IV 8 hourly) was supplemented, both the patient improved clinically along with serum sodium level. Patients with IAD usually fare relatively well during unstressed periods until intervening events spark off an acute adrenal crisis, stress doses of glucocorticoids should be supplemented during these events.

\section{Conclusion}

IAD is a potentially fatal condition and difficult to diagnose. Rarely IAD patients can present as hyponatremia and non-specific symptoms. A high index of suspicion should be maintained in such cases. Hyponatremia often occurs in elderly patients and a thorough evaluation as to its etiology should be sought before committing to a premature diagnosis.

\section{Funding: Nil, Conflict of interest: None Permission of IRB: Yes}

\section{References}

1. Dillard GM, Bodel P. Studies on steroid fever II. Pyrogenic and anti-pyrogenic activity in vitro of some endogenous steroids of man. Journal of Clinical Investigation. 1970;49(12):2418-2426. doi: 10.1172/JCI106461.

2. Goto Y, Tatsuzawa K, Aita K, et al. Neurological symptoms in a patient with isolated adrenocorticotropin deficiency: case report and literature review. BMC Endocrine Disorders. 2016; 16:2. doi:10.1186/s12902-015-0082-6.

3. Michael Y. Torchinsky, Robert Wineman, and George W. Moll, "Severe Hypoglycemia due to Isolated ACTH Deficiency in Children: A New Case Report and Review of the Literature," International Journal of Pediatrics, vol. 2011. doi:10.1155/2011/784867. 
4. R. C. Page and F. Alford, Adrenocorticosteroid deficiency: an unusual cause of fever of unknown origin. Postgrad Med J. 1993 May; 69(811): 395396.

5. Abhay Gundgurthi, MK Garg, MK Dutta, R Pakhetra. Intramuscular ACTH Stimulation Test for Assessment of Adrenal Function. J Assoc Physicians India 2013 May; 61(5):320-4.
6. Saepudin et al. BMC Cardiovascular Disorders (2015); 15:88. Doi: 10. 1186 /s12872-015-00 $82-5$.

7. Stacpool P. W., Interlandi J. W., Nicholson E., and Rabin D.. 1982. Isolated ACTH deficiency; a heterogeneous disorder. Critical review and report of four new cases. Medicine (Baltimore). 1982 Jan; 61(1):13-24.

\section{How to cite this article?}

Bhardwaj L.M, Bhattacharyya P. C, Borthakur S, Sarma A, Barua S. Two Cases of Isolated ACTH Deficiency Presenting As Hyponatremia - Case Report. Int J Med Res Rev 2017;5(08):825-828.doi:10.17511/ijmrr. 2017.i08.09. 